\title{
Gas Chromatographic Determination of Prochloraz in Ten Herbal Medicines
}

\author{
Jialun $\mathbf{W u}^{1 *}$, Jing Zhao', Tianyu Wang ${ }^{1}$, Aoran Chen ${ }^{1}$ and Jian $\mathrm{Xue}^{2}$
}

${ }^{1}$ Ministry of Agriculture Key Laboratory of Molecular Biology of Crop, Pathogens and Insects, Institute of Pesticide and Environmental Toxicology, Zhejiang University, Hangzhou 310029, China

${ }^{2}$ Institute of Medicinal Plant Development, Chinese Academy of Medical Sciences and Peking Union Medical College, Beijing 100193 China

\begin{abstract}
A method for determining prochloraz in ten herbal medicines is described. Pesticide standards were fortified into herbal medicines at 3 levels $(0.005,0.01$ and $0.05 \mathrm{mg} / \mathrm{kg})$. Prochloraz reacts with pyridine hydrochloride and generates a hydrolysate, the 2,4,6-trichlorophenol which responded intensively in GC-ECD. The results showed average recoveries were between $76.6 \%$ and $105.1 \%$. The method evidenced good accuracy and precision for monitoring prochloraz in ten herbal medicine samples. The limit of quantification (LOQ) was $0.005 \mathrm{mg} / \mathrm{kg}$. It is linear from $0.005 \mathrm{mg} / \mathrm{L}$ to $2.000 \mathrm{mg} / \mathrm{L}$. The regression equation is $\mathrm{y}=3816.1 \mathrm{x}-7.7835, \mathrm{R}=0.9997$.
\end{abstract}

Keywords: Prochloraz; Fungicide; Gas chromatography; 2,4,6-Trichlorophenol; Herbal medicine

\section{Introduction}

Herbal Medicines have been prevailing for thousands of years in China, which are the treasure to all human beings. With the increasing demand for herbal medicines, most of them are cultivated in fields. Plant disease, pest insects and weeds, which results in yield loss and lower quality, are the primary limitation to the production. Currently, it is a main method to use pesticides in medicinal herb fields for controlling the damage caused by Plant disease, pest insects and weeds. Prochloraz (N-propyl-N-[2-(2,46-trichlorophenoxy)-ethyl] imidazole-1-carboxamide) (Figure 1) is a non-systemic imidazole fungicide, an ergosterol biosynthesis inhibitor with contact and translaminar, protectant and eradicant activity. It is used in agriculture and horticulture against various plant diseases, especially Ascomycetes and Fungi Imperfecti. It is used to control foliar diseases of cereals (Pseudocercosporella, Pyrenophora, Rhynchosporium and Septoria spp.), field crops (such as Alternaria, Botrytis, Pyrenopeziza and Sclerotinia in oilseed rape, Ascochyta and Botrytis in legumes, Pyricularia in rice), fruit (blossom blight) and vegetables (anthracnose) [1]. In china, it is also used in medicinal herb fields.

Several analytical methods of prochloraz residues have been reported. Most of them were on vegetable, fruit, and cereals [2-15], some is on soil and water[16,17]. It is not found on herbal medicines. Ginseng Rodix ET Rhizoma, Rhizoma Atractylodis Macrocephalae, Isatidis Radix, Curcumae Rhizoma, Dioscoreae Rhizoma, Crataegi Fructus, Acanthopanacis Senticosi Radix, Lonicerae Japonicae Flos, Lorydalis Rhizoma and Radix Astragali are conventional Chinese herbal medicines that are artificially planted. Prochloraz is a popularly used fungicide in these medicinal herb fields. The object of this work was to develop a method for determining prochloraz in herbal medicines. It is significant to find, control prochloraz residue and improve the quality of herbal medicines.

\section{Experimental}

\section{Apparatus}

a. Gas chromatograph.-Agilent 7890A equipped with an ECD detector (Agilent Technology Company, USA).

b. Vacuum pump.- SHB-III-A(Hangzhou Dawei Scientific Ltd., PRC). c. Rotary evaporator-LABOROTA 4010(Heidolph Instruments, Germany).

d. Ultrasonic Machine.-KQ5200DE (KunShan Ultrasonic Instruments Co., Ltd, PRC).

e. Grinder.-DD-01(Wenling Linda Machine Ltd., PRC)

\section{Reagents and materials}

- Solvents.-All organic solvents, e.g., acetone, dichloromethane, petroleum ether, hydrochloric acid and concentrated sulfuric acid, analytical grade (made in China).

- Sodium sulfate anhydride.- Analytical grade and heated $8 \mathrm{~h}$ at $450^{\circ} \mathrm{C}$ and stored in a tightly capped bottle until used.

- Celite 545.-(Fluke).

- Pesticide standards solution.-Prochloraz which was provided by Dr. Ehrenstorfer. $500 \mathrm{mg} / \mathrm{L}$ dissolve in methanol. 2,4,6-trichloro-phenol were provided by DIMEE TECHNOLOGY in Hexane. Pyridine hydrochloride was provided by Hangzhou Faojing Fine Chemical Industry Ltd., Zhejiang, PRC.

- Herbal medicines. - buy from market or supplied by Medicinal herb GAP plantation.

\section{Extraction}

Dried samples were pulverized and passed through a 20-mesh screen. Weigh $4 \mathrm{~g}$ sample in a $250 \mathrm{ml}$ screw-stop sample bottle, add $5 \mathrm{ml}$

*Corresponding author: Jialun Wu, Ministry of Agriculture Key Laboratory of Molecular Biology of Crop., Pathogens and Insects, Institute of Pesticide and Environmental Toxicology, Zhejiang University, Hangzhou 310029, China, Tel: 0086057186971221 ; Fax number: 00860571 86971221; E-mail: jlwu@zju. edu.cn

Received May 25, 2011; Accepted July 19, 2011; Published July 21, 2011

Citation: Wu J, Zhao J, Wang T, Chen A, Xue J (2011) Gas Chromatographic Determination of Prochloraz in Ten Herbal Medicines. Pharm Anal Acta 2:128 doi:10.4172/2153-2435.1000128

Copyright: ( $2011 \mathrm{Wu} \mathrm{J}$, et al. This is an open-access article distributed under the terms of the Creative Commons Attribution License, which permits unrestricted use, distribution, and reproduction in any medium, provided the original author and source are credited. 
$1 \mathrm{~mol} / \mathrm{L}$ hydrochloric acid and $60 \mathrm{ml}$ acetone, ultrasonic extract for 30 minutes. Vacuum filtrate with Buchner funnel (add a filter paper and suitable celite545). Elute the sample bottle with $40 \mathrm{ml}$ acetone. Collect filtrate into a $250 \mathrm{ml}$ flask and concentrate to $3 \sim 5 \mathrm{ml}$ in a rotary vacuum evaporate at $45^{\circ} \mathrm{C}$. The remaining solution was transferred to a 250 $\mathrm{ml}$ separating funnel, add $40 \mathrm{ml} 10 \%$ sodium chloride water solution. Extract with $2 \times 50 \mathrm{ml}$ dichloromethane. Collect organic phase which passed through $10 \mathrm{~g}$ sodium sulfate anhydrous into a $250 \mathrm{ml}$ Florence flask and concentrate to $5 \sim 10 \mathrm{ml}$ in a rotary vacuum evaporate at $48^{\circ} \mathrm{C}$. Transfer concentrated solution into a $50 \mathrm{ml}$ round-bottom flask, rinse the Florence flask with $20 \mathrm{ml}$ dichloromethane, combine extracts carefully and concentrate to almost $1 \mathrm{ml}$ in a rotary vacuum evaporate at $48^{\circ} \mathrm{C}$ then evaporate to completely dry with soft nitrogen stream.

\section{Hydrolysis and cleanup}

Add $2 \mathrm{~g}$ pyridine hydrochloride into the flask, connecting with a condenser pipe. Heated up to $220 \sim 240^{\circ} \mathrm{C}$ in a thermostatic oil bath for 1 hour. Wash the condenser pipe with $10 \mathrm{ml}$ distilled water after cooling. Put the stopper on the flask and shake to dissolve completely. Transfer the solution into a $250 \mathrm{ml}$ separating funnel and elute the flask several times with $30 \mathrm{ml} 0.01 \mathrm{~mol} / \mathrm{L}$ sodium hydroxide solution, collect all solution to the separating funnel. Decontaminate with $2 \mathrm{x}$ $20 \mathrm{~mL}$ petroleum-ether/toluene $(4: 1, \mathrm{v} / \mathrm{v})$, and the organic phase was discarded. Adding $3 \mathrm{ml} 1 \mathrm{~mol} / \mathrm{L}$ hydrochloric acid, extract with $2 \times$ $30 \mathrm{~mL}$ petroleum ether, collect organic phase which passed through $10 \mathrm{~g}$ sodium sulfate anhydrous into another $250 \mathrm{ml}$ separating funnel. Add $10 \mathrm{ml}$ concentrated sulfuric acid into $250 \mathrm{ml}$ separating funnel, shake for 1 minute. Discard concentrated sulfuric acid layer. Repeat 2 times until concentrated sulfuric acid layer is clear. Wash organic phase with $2 \times 40 \mathrm{~mL} 10 \%$ sodium chloride water solution discard water solution. Collect organic phase into the $250 \mathrm{ml}$ flask and concentrate to almost $1 \mathrm{ml}$ in a rotary vacuum evaporate at $48^{\circ} \mathrm{C}$ then evaporate to completely dry with soft nitrogen stream. Add $2 \mathrm{ml} \mathrm{n}$-hexane and

\begin{tabular}{|c|c|c|c|c|c|c|}
\hline Sample name & Fortified concen. $(\mathrm{mg} / \mathrm{kg})$ & \multicolumn{3}{|c|}{ Recovery(\%) } & Average recovery(\%) & $\operatorname{RSD}(n=3) / \%$ \\
\hline \multirow{3}{*}{ Ginseng Rodix ET Rhizoma } & 0.005 & 102.5 & 97.1 & 103.8 & 101.1 & 3.5 \\
\hline & 0.010 & 106.3 & 96.2 & 98.7 & 100.4 & 5.2 \\
\hline & 0.050 & 103.8 & 100.2 & 108.2 & 104.1 & 3.9 \\
\hline \multirow{3}{*}{ Rhizoma Atractylodis Macrocephalae } & 0.005 & 91.2 & 93.4 & 95.1 & 93.2 & 2.1 \\
\hline & 0.010 & 96.2 & 92.2 & 93.0 & 93.8 & 2.3 \\
\hline & 0.050 & 102.4 & 98.8 & 97.9 & 99.7 & 2.4 \\
\hline \multirow{3}{*}{ Isatidis Radix } & 0.005 & 86.7 & 85.7 & 89.1 & 87.2 & 2.0 \\
\hline & 0.010 & 107.1 & 93.4 & 94.1 & 98.2 & 7.9 \\
\hline & 0.050 & 108.4 & 106.7 & 100.3 & 105.1 & 4.1 \\
\hline \multirow{3}{*}{ Curcumae Rhizoma } & 0.005 & 79.4 & 85.4 & 83.6 & 82.8 & 3.7 \\
\hline & 0.010 & 93.9 & 94.2 & 91.1 & 93.1 & 1.8 \\
\hline & 0.050 & 96.7 & 95.1 & 97.8 & 96.5 & 1.4 \\
\hline \multirow{3}{*}{ Dioscoreae Rhizoma } & 0.005 & 76.8 & 74.8 & 78.2 & 76.6 & 2.2 \\
\hline & 0.010 & 79.8 & 79.2 & 80.7 & 79.9 & 0.9 \\
\hline & 0.050 & 86.1 & 83.7 & 90.8 & 86.9 & 4.2 \\
\hline \multirow{3}{*}{ Crataegi Fructus } & 0.005 & 88.8 & 86.0 & 84.3 & 86.4 & 2.6 \\
\hline & 0.010 & 91.9 & 89.2 & 93.4 & 91.5 & 2.3 \\
\hline & 0.050 & 90.8 & 96.4 & 95.8 & 94.3 & 3.3 \\
\hline \multirow{3}{*}{ Acanthopanacis Senticosi Radix } & 0.005 & 81.2 & 83.1 & 85.5 & 83.3 & 2.6 \\
\hline & 0.010 & 97.6 & 96.6 & 92.2 & 95.5 & 3.0 \\
\hline & 0.050 & 106.4 & 105.2 & 100.7 & 104.1 & 2.9 \\
\hline \multirow{3}{*}{ Lonicerae Japonicae Flos } & 0.005 & 86.2 & 88.0 & 84.7 & 86.3 & 1.9 \\
\hline & 0.010 & 92.5 & 99.5 & 93.1 & 95.0 & 4.1 \\
\hline & 0.050 & 88.4 & 96.4 & 95.5 & 93.4 & 4.7 \\
\hline \multirow{3}{*}{ Lorydalis Rhizoma } & 0.005 & 83.6 & 85.1 & 85.7 & 84.8 & 1.3 \\
\hline & 0.010 & 102.8 & 98.4 & 98.1 & 99.8 & 2.6 \\
\hline & 0.050 & 95.2 & 93.3 & 95.6 & 94.7 & 1.3 \\
\hline \multirow{3}{*}{ Radix Astragali } & 0.005 & 79.8 & 93.3 & 86.0 & 86.4 & 7.8 \\
\hline & 0.010 & 91.8 & 88.5 & 90.4 & 90.2 & 1.8 \\
\hline & 0.050 & 85.7 & 96.2 & 95.3 & 92.4 & 6.3 \\
\hline
\end{tabular}

Table 1: Recoveries of prochloraz in ten medicinal herb samples. 


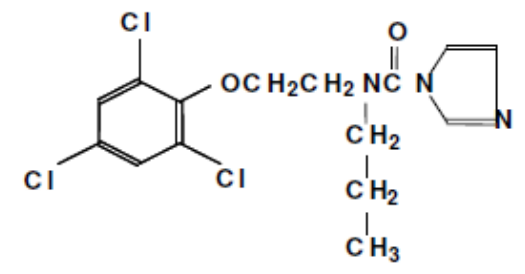

Figure 1: Structural formula of prochloraz.

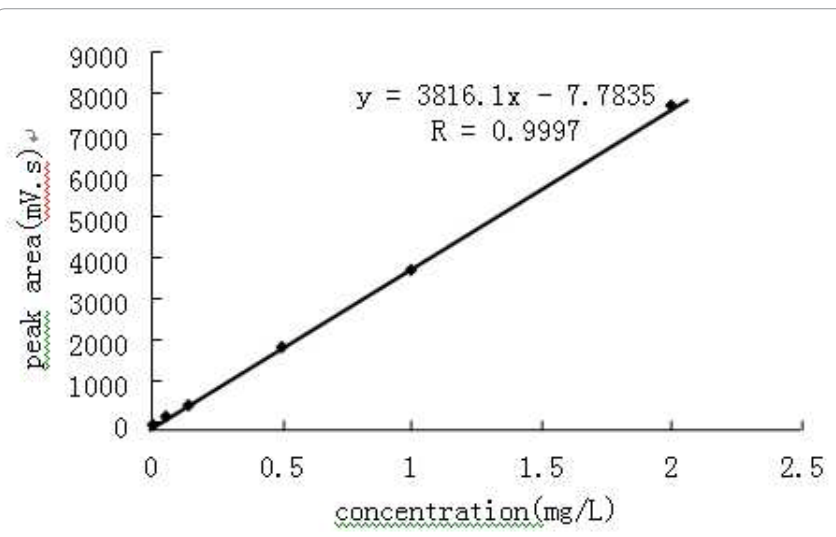

Figure 2: Calibration curve for prochloraz (concentration from 0-2.0 mg/L).

mixed for determination.

\section{Condition of gas chromatograph}

The analysis of 2,4,6-trichlorophenol was carried out by GC using an Agilent 7890A with an ECD, a capillary chromatographic column SE- $54,30 \mathrm{~m} \times 0.32 \mathrm{~mm} \times 0.25 \mu \mathrm{m}$ film thickness. The temperature program applied as follows: $100^{\circ} \mathrm{C}$ for $1 \mathrm{~min}, 100-160^{\circ} \mathrm{C}$ at $15^{\circ} \mathrm{C} / \mathrm{min}$, $160^{\circ} \mathrm{C}$ for $3 \mathrm{~min}, 160-180^{\circ} \mathrm{C}$ at $2^{\circ} \mathrm{C} / \mathrm{min}, 180^{\circ} \mathrm{C}$ for $5 \mathrm{~min}, 180-250^{\circ} \mathrm{C}$ at $30^{\circ} \mathrm{C} / \mathrm{min}$ and $250^{\circ} \mathrm{C}$ for $5 \mathrm{~min}$. The injector port temperature was $250^{\circ} \mathrm{C}$, detector temperature, $300^{\circ} \mathrm{C}$; Nitrogen carrier gas flow rate, 1 $\mathrm{ml} / \mathrm{min}$. up gas, $30 \mathrm{ml} / \mathrm{min}$ and septum purge flow to appropriate levels, $3 \mathrm{ml} / \mathrm{min}$. The injection port type: splitless, inject amount was $1 \mu \mathrm{l}$.

\section{Standard sample}

Respectively add $0.005,0.010,0.050,0.500,1.000,2.000 \mathrm{mg} / \mathrm{L}$ standard sample into a round-bottle flask and evaporate to completely dry with nitrogen. Next processing step according to 2.4 and 2.5 described.

\section{Results and Discussion}

The method used demonstrated acceptable performance for the prochloraz residue analysis in ten herbal medicines. Under the chromatographic conditions described, good linear and correlation coefficient was achieved for the compound studied. Replicates $(n=3)$ of six standard pesticide solutions of different concentrations were found to be linear in the range from 0.005 to $2.0 \mathrm{mg} / \mathrm{L}$ for the chromatographic techniques (Figure 2). The regression equation for the calibration curve was $y=3816.1 x-7.7835$. The correlation coefficients obtained for the prochloraz was 0.9997 . The limit of quantification (LOQ) for prochloraz under study was $0.005 \mathrm{mg} / \mathrm{kg}$. Validation of the method for this fungicide was performed by fortified recovery study with prochloraz at $0.005,0.01$ and $0.05 \mathrm{mg} / \mathrm{kg}$ levels. For analyses by this method, average recovery ranges of prochloraz from ten herbal medicines were $76.6-105.1 \%$. Relative standard deviations (RSD) were $0.9-7.9 \%$. The detail results are shown in Table1. Some typical chromatograms of 2,4,6-trichloro-phenol standard, fortified $0.5 \mathrm{mg} /$ $\mathrm{kg}$ prochloraz with no herbal medicines and solvent check unfortified prochloraz are shown in Figure 3-5. Typical chromatograms of herbal medicine samples untreated and fortified $0.5 \mathrm{mg} / \mathrm{kg}$ of prochloraz are shown in Figure 6, 7.

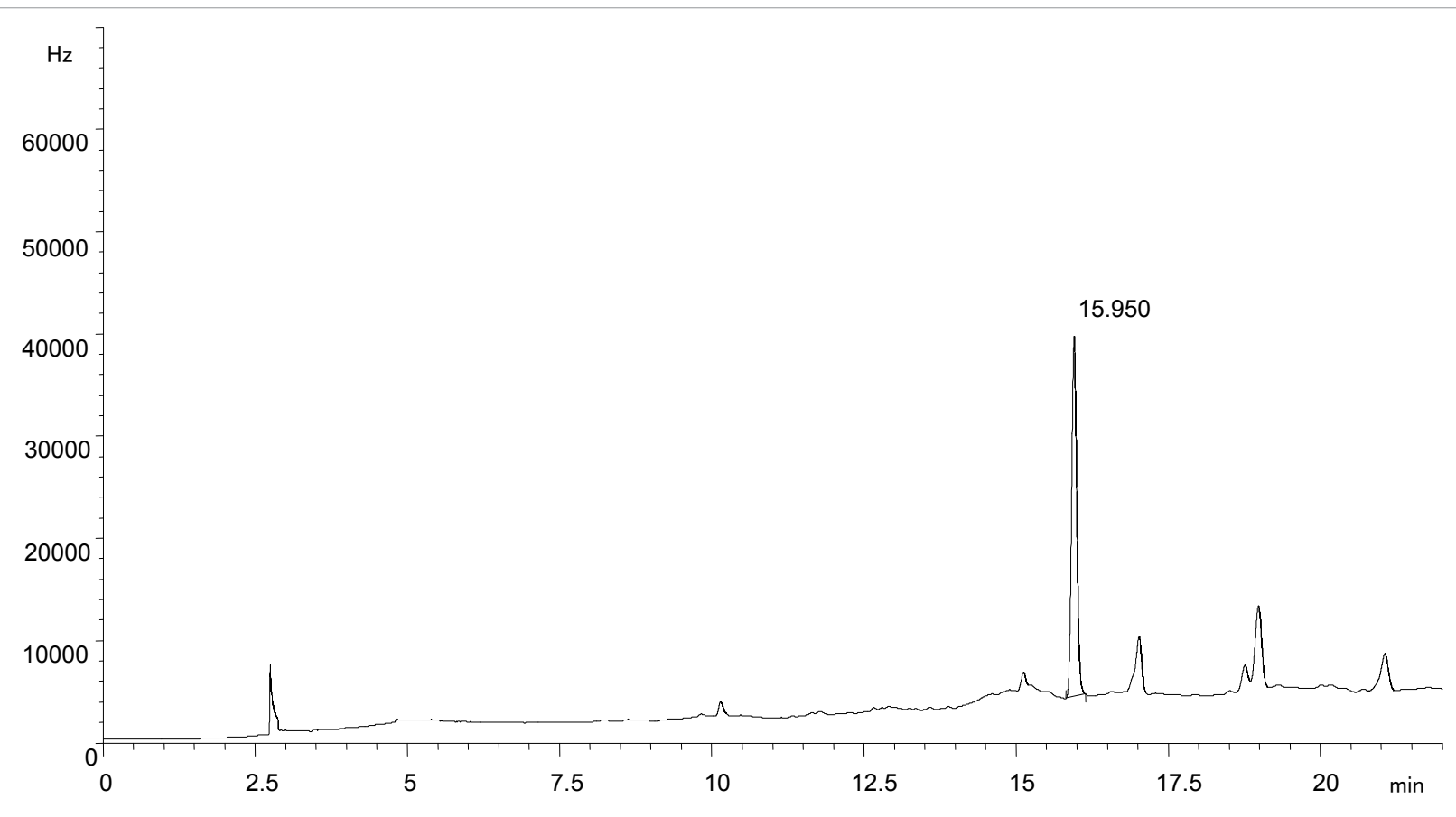

Figure 3: Chromatogram of 0.5mg/kg 2,4,6-trichloro-phenol. 


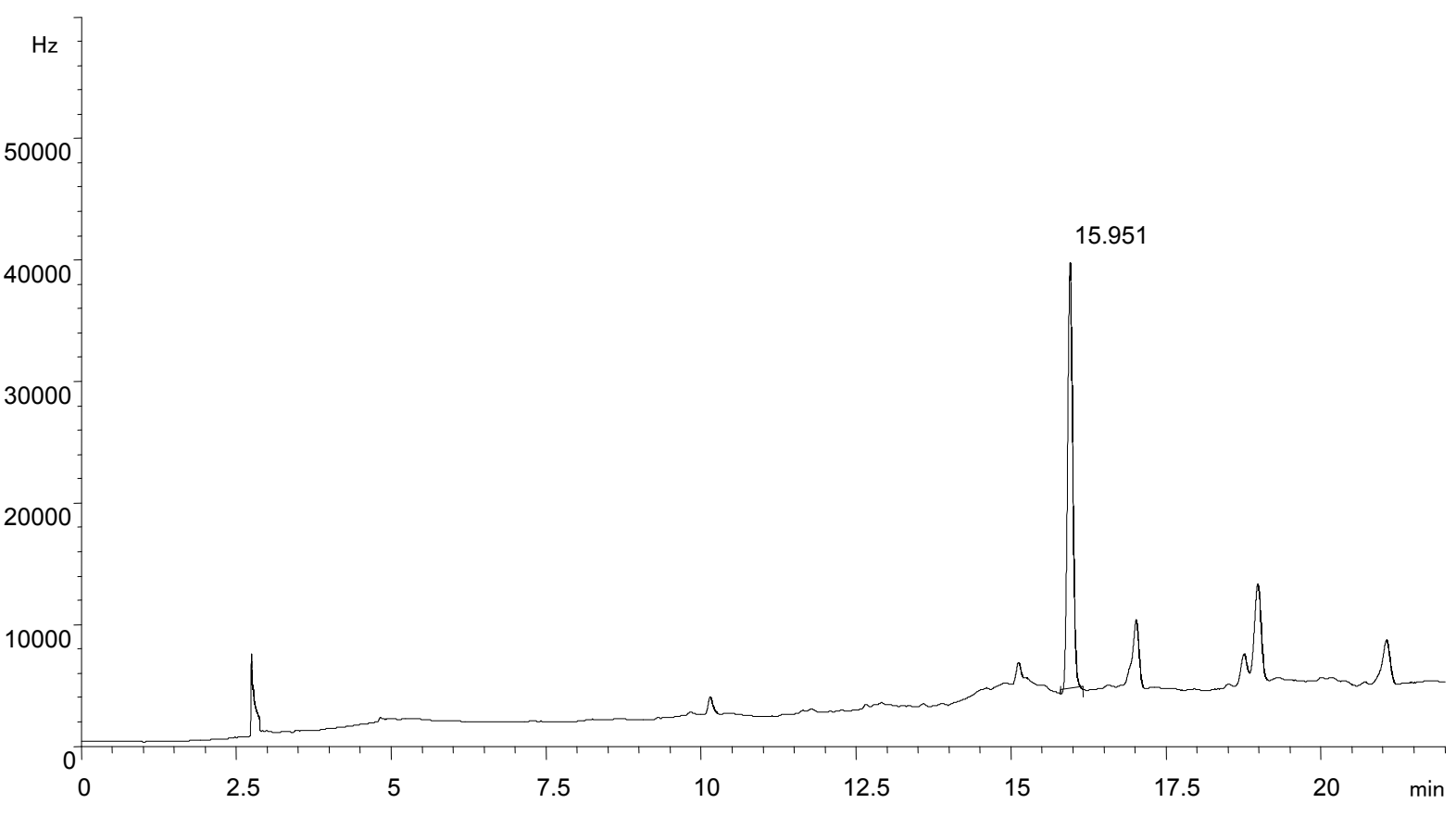

Figure 4: Chromatogram of fortified $0.5 \mathrm{mg} / \mathrm{kg}$ of prochloraz standard (no sample).

$\mathrm{Hz}$

60000

50000

40000

30000

20000

10000

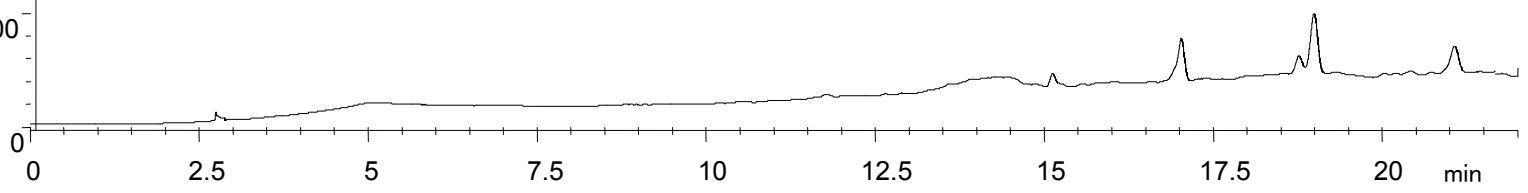

Figure 5: Chromatogram of solvent check of unfortified prochloraz.

In hydrolysis, the rate that prochloraz hydrolyzes to 2,4,6-trichlorophenol would influence reliability and veracity of the method. On the basis of stechiometry, the prochloraz is hydrolysed with pyridine hydrochloride to break down all components to 2,4,6-trichlorophenol. This hydrolysate is then cleaned-up by extraction into the aqueous layer with alkali and re-extraction into petroleum ether after acidification. Total 2,4,6-trichlorophenol residues are determined by gas chromatography with electron capture detector, and the results are expressed as prochloraz equivalents by correcting the measured 2,4,6-trichlorophenol concentration for the molecular weight factor of 1.9. The tested result of prochloraz standard showed the conversion rate was above $98 \%$ under the test condition.

FAO and WHO reported MRLs of prochloraz in cereal grains and rape seed were $0.05 \mathrm{mg} / \mathrm{kg}$ (France), in mushroom were 0.05 


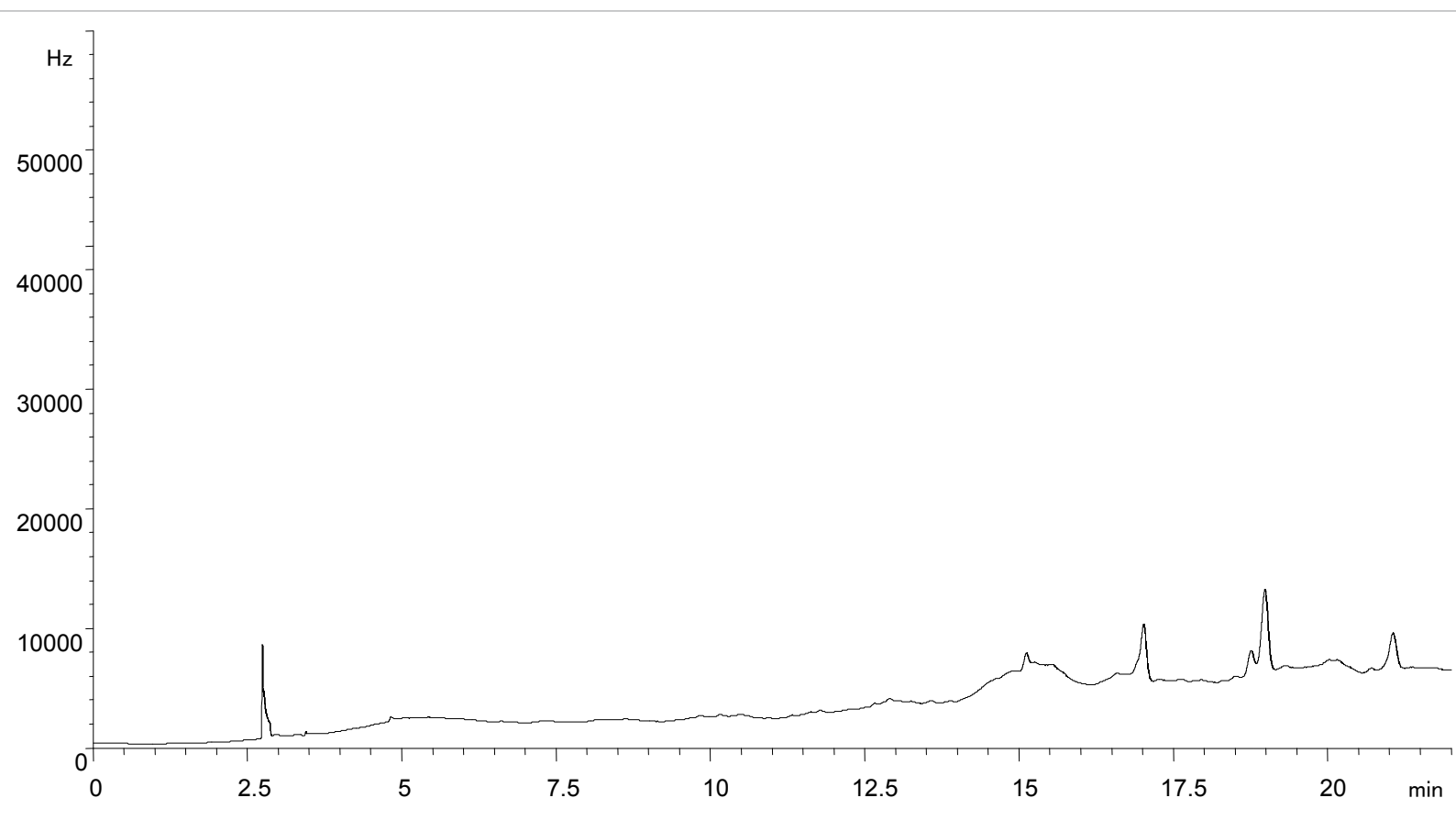

Figure 6: Chromatogram of Rhizoma Curcumae unfortified prochloraz.

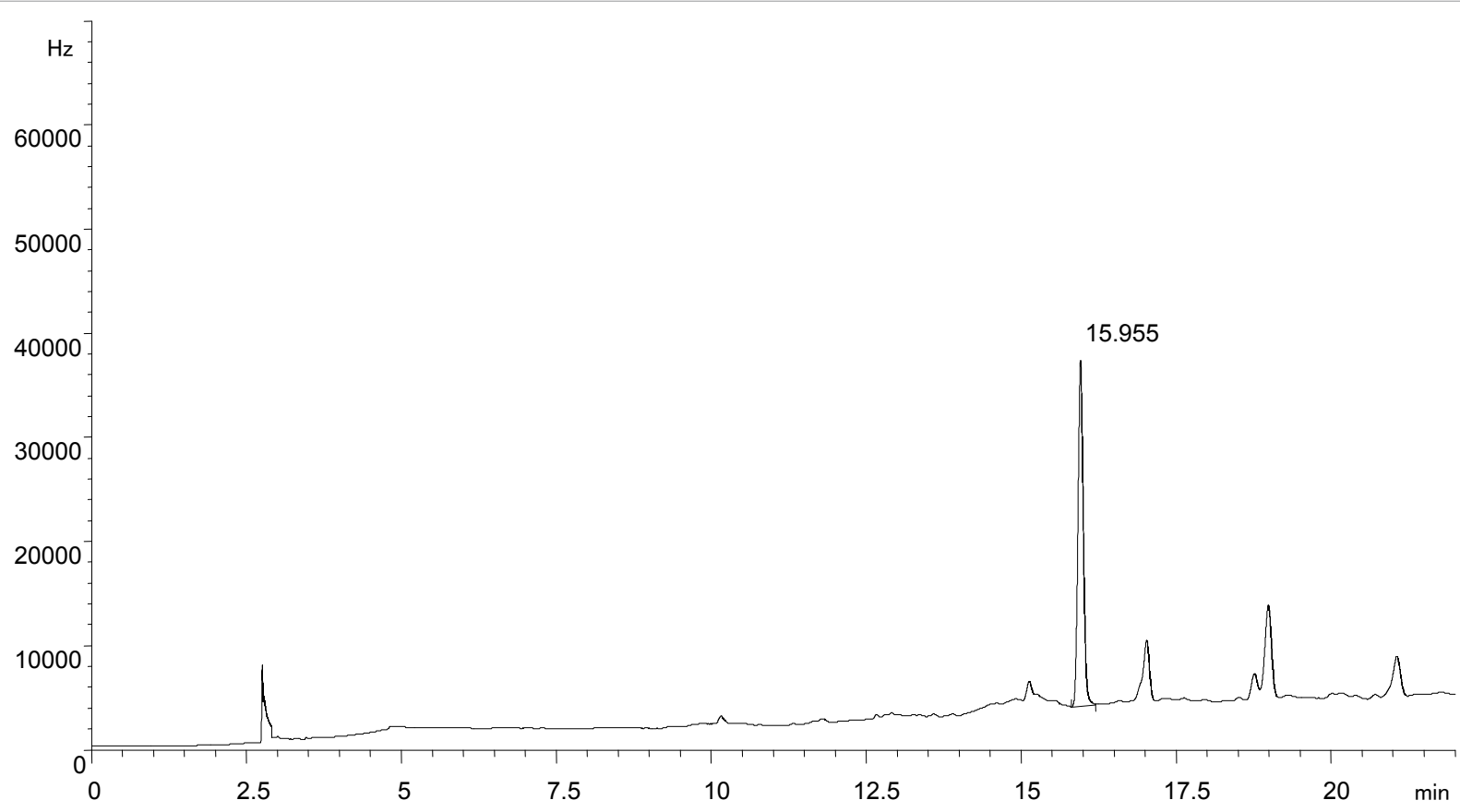

Figure 7: Chromatogram of Rhizoma Curcumae fortified with $0.5 \mathrm{mg} / \mathrm{kg}$ of prochloraz.

$\mathrm{mg} / \mathrm{kg}$ (The Netherlands), in other products were $0.01 \mathrm{mg} / \mathrm{kg}$ (The Netherlands)[18]. By now, no any MRL of prochloraz was established in herbal medicines. In view of many countries usually set $0.01 \mathrm{mg} /$ $\mathrm{kg}$ as a criteria for no MRL products, such as "Positive list system of Japan", the method is available for herbal medicines. Paoli et al (1997) reported a GC-ECD method for determining 2, 4, 6-trichlorophenol as prochloraz in vegetable, fruit and wheat, and the LOQ were 0.01 -
$0.5 \mathrm{mg} / \mathrm{kg}$. Blasco et al (2001) developed a LC-MS and LC-UV method for determining prochloraz in fruits and vegetables. The LOQ was 0.1 $\mathrm{mg} / \mathrm{kg}$ (LC-MS) and $0.5 \mathrm{mg} / \mathrm{kg}$ (LC-UV). Polese et al (2006) described results of prochloraz, which determined as 2,3,4-trichlorophenol, and its metabolite residue in ginger. The LOQ of GC-ECD method was 0.1 and $0.2 \mathrm{mg} / \mathrm{kg}$, respectively. The method of this paper is more sensitive compared with published papers in terms of the LOQ. The method described here has been successfully used to determine prochloraz in 
ten Chinese herbal medicines. The GC-ECD method should be readily applicable to other Chinese herbal medicines.

\section{Acknowledgments}

We express our gratitude to Jilin Hongjiu Biotechnology Ltd., Jilin Good Agricultural Practice plantation of Ginseng and Mr. Jiewei Zou for providing Chinese herbal medicine samples.

\section{References}

1. Food and Agriculture Organization of the United Nations (2009) FAO SPECIFICATIONS AND EVALUATIONS FOR PROCHLORAZ, p.12

2. Paoli MDe, Barbina MT, Damiano V, Fabbro D and Bruno R (1997) Simplified Determination of Combined Residues of Prochloraz and its Metabolites in Vegetable, Fruit and Wheat Samples by Gas Chromatography, Journal of Chromatography A, 765:127-131

3. Polese L, Jardim EFG, Navickiene S, Brito NM, Ribeiro ML (2006) Prochloraz Residue Levels in Ginger Submitted to Sporatak 450 CE Postharvest Treatment, Ecletica Quimca, 31: 59-63

4. Blasco C, Pico Y, Manes J, Font G (2002) Determination of fungicide residues in fruits and vegetables by liquid chromatography-atomspheric pressure chemical ionization mass spectrometry, J. Chromatography A, 947:227-235.

5. Kastanias MA, Chrysayi-Tokousbalides M, Coward S, Philippoussis A Diamantopoulou P (2006) Residue evaluation of the azole fungicides prochloraz and tebuconazole in the white mushroom agaricus bisporus, Bull. Environ Contam Toxicol 77(1):149-154

6. Lafuente MT, Tadeo JL (1985) Residues analysis of posrharvest imidazole fungicides in citrus fruit by HPLC and GLC. Environmental Anal Chem 22:99108.

7. Rodriguez R, Boyer I, Font G, Pico Y (2001) Capillary zone electrophoresis for the determination of thiobendazole, prochloraz and procymidone in grapes. Analyst 126(2): 2134-2138.

8. Dreassi E., Zanfini A., Zizzari T. A., Rosa C.L., Botta M. and Corbini G. (2010) $\mathrm{Lc} / \mathrm{Esi} / \mathrm{MS} / \mathrm{MS}$ determination of postharvest fungicide residues in citrus juices, Food Science and Technology, 43(9) 1301-1306
9. Yin G., Han H. and Yuan H. (2007) Gas chromatography determination of prochloraz in mangoes, Chinese Journal of South China University of Tropical Agriculture 13(3)15-17

10. Li T, Wang Y, Liu B, Gao X (2010) Residual detection and degradation dynamics of prochloraz in Ya pear. Chinese Journal of South China Agricultura University 31(2): 36-39.

11. Yu C., He B. and Yan J. (2004) Analysis of prochloraz residue in orange Chinese Journal of Modern Agrochemicals, 3(3)28-29

12. Liu X., Chen P., Shen J., Cheng Y. and Chen H. (2007) Analysis of prochloraz residue in mushroom with liquid chromatography/Mass spectrometry, Chinese Journal of Analytical Science, 23(5)523-526.

13. Liu X., Chen P., Cheng Y., Li S., Chen H. and Wu M. (2006) Study on residue detection and degradation in rapeseed and soil, Chinese Journal of Oil Crop Science, 28(3)354-57

14. Han L., Qian C., Jiang C. and Wang W. (2005) Residue detection and degradation of prochloraz and its metabolites in rice, Chinese Journal of Pesticide Science, 7(1):54-58

15. Cheng L, Dong F., Liu X, Zhang Y, Chen W, et al. (2009) Simplified method fo determination of fungicide prochloraz residues in wheat using QuEChERS and UPLC-MS/MS Chinese Journal of Pesticide Science 11(3): 357-361.

16. Aktar MW, Sengupta D, Purkait S, Ganguly M, Paramasivam M (2008) Degradation dynamics and dissipation kinetics of an imidazole fungicide (Prochloraz) in aqueous medium of varying pH, Interdiscip Toxicol 1(3-4): 203205

17. Andreas Höllrigl-Rosta, Robert Kreuzig, Müfit Bahadir (1999) Investigations on the metabolic fate of prochloraz in soil underfield and laboratory condition. Pesticide Science 55: 531-538

18. Food and Agriculture Organization of the United Nation (1985) FAO and WHO pesticide residues in Food-1983, Roma. 